\title{
Article \\ Micro Push-Out Bond Strength of Resin Composite to Dentin in Primary Dentition Using Three Universal Adhesives with Different pH: An In Vitro Study
}

\author{
Regina María Del Río Carrillo ${ }^{1}$, Pedro Molinero-Mourelle ${ }^{2,3, *}$, , Vicente Vera ${ }^{2}$, Pablo Romero Villaba ${ }^{4}$, \\ Elizabeth Casañas $^{5}{ }^{(D}$, Manrique Fonseca ${ }^{3}{ }^{(0)}$, Vicente Vera-Gonzalez ${ }^{2}$ and María Rosa Mourelle-Martinez ${ }^{1}$ \\ 1 Department of Dental Clinical Specialties, School of Dentistry, Complutense University of Madrid, \\ 28040 Madrid, Spain; reginadelriocarrillo@ucm.es (R.M.D.R.C.); mrmourel@ucm.es (M.R.M.-M.) \\ 2 Department of Conservative Dentistry and Orofacial Prosthetics, Faculty of Dentistry, \\ Complutense University of Madrid, 28040 Madrid, Spain; vicevera@ucm.es (V.V.); \\ vveragon@ucm.es (V.V.-G.) \\ 3 Department of Reconstructive Dentistry and Gerodontology, School of Dental Medicine, University of Bern, \\ 3010 Bern, Switzerland; manrique.fonseca@zmk.unibe.ch \\ 4 Department of Dentistry, Faculty of Biomedical Sciences and Health, European University of Madrid, \\ 28670 Madrid, Spain; pablo.romero@universidadeuropea.es \\ 5 ORALMED Research Group, Department of Dental Clinical Specialties, School of Dentistry, \\ Complutense University of Madrid, 28040 Madrid, Spain; ecasanasgil@gmail.com \\ * Correspondence: pedromol@ucm.es or pedro.molineromourelle@zmk.unibe.ch; Tel.: +34-913941922
}

Citation: Del Río Carrillo, R.M.; Molinero-Mourelle, P.; Vera, V.; Romero Villaba, P.; Casañas, E.; Fonseca, M.; Vera-Gonzalez, V.; Mourelle-Martinez, M.R. Micro Push-Out Bond Strength of Resin Composite to Dentin in Primary Dentition Using Three Universal Adhesives with Different $\mathrm{pH}$ : An In Vitro Study. Appl. Sci. 2021, 11, 6349. https://doi.org/10.3390/app11146349

Academic Editor: Giuliana Muzio

Received: 19 May 2021

Accepted: 6 July 2021

Published: 9 July 2021

Publisher's Note: MDPI stays neutral with regard to jurisdictional claims in published maps and institutional affiliations.

Copyright: (c) 2021 by the authors. Licensee MDPI, Basel, Switzerland. This article is an open access article distributed under the terms and conditions of the Creative Commons Attribution (CC BY) license (https:/ / creativecommons.org/licenses/by/ $4.0 /)$.

\begin{abstract}
To evaluate the bond strength of different universal adhesives on deciduous tooth dentine and their relationship with the composition and potential of hydrogen $(\mathrm{pH})$. Methods: An in vitro micro push-out test on 150 samples $(n=50)$ per group per adhesive, namely, Adhese Universal (ADH; Ivoclar Vivadent), Futurabond U (FUT; Voco GmbH) (Test), and Scotchbond Universal with pre-conditioning (SCO; 3M) (Control), to record bond strength (BS) and type of adhesive failure. Results: The results of the different adhesives (megapascals (MPa)) varied, showing no statistical significance. The corresponding averages are in MPa: ADH, $13.66 \pm 2.81$; FUT, $14.48 \pm 2.88$; SCO, $14.98 \pm 3.96$. Additionally, the frequency of type of failure was as follows: mixed $(60.7 \%)$, adhesive $(27.3 \%)$, and cohesive $(12 \%)$. Conclusions: SCO, with a $\mathrm{pH}$ of 2.7 , showed greater resistance to fracture, while FUT, with a $\mathrm{pH}$ of 2.3 and no pre-conditioning, approached the same values, being a one-step adhesive. No relationship was found between failure and type of adhesive.
\end{abstract}

Keywords: universal adhesives; micro push-out; deciduous dentition; dentine

\section{Introduction}

Current adhesive systems allow for the improvement of clinical procedures due to their component chemicals and mechanism of action, reducing the operating time of application, handling of use, and side effects on the patient [1]. Universal or multi-mode adhesives are essentially one-step adhesives, combining an acidic primer and adhesive in a single solution and allowing a self-etching, total, or selective etching technique application. These systems can be applied to different dental surfaces, namely, wet and dry demineralized dentine [2,3], enamel, and even ceramic materials, composites, and metals [4].

Universal adhesives can be considered dependent materials [5] as their components modify their mechanical properties [6,7]. The adhesive composition is mainly based on a mixture of resin monomers HEMA (facilitates resin diffusion within the collagen network) and Bis-GMA (decreases shrinkage by polymerization and is fast curing to improve the mechanical properties of the polymer), inhibitors or stabilizers (antioxidants capable of eliminating free radicals, preventing spontaneous initiation and propagation of polymerization), solvents (which decrease viscosity and promote resin filtration), photoinitiators 
(which contribute to the formation of a stable adhesive interface), and filler particles [8,9]. Universal adhesive systems have a composition similar to self-etching adhesives [3]. They contain phosphorus monomers, mainly 10-MDP (10-methacryloyloxydecil dihydrogen phosphate), that generate ionic bonds with hydroxyapatite by means of nano-layers (nanolayering) [10]. This monomer presents a chemical bond with the hydroxyapatite present in dentine and enamel.

To facilitate the use of universal adhesives in clinical situations, whether etching is required or not, the manufacturers mix resin monomers with lower acidity in appropriate concentrations [11], increasing the potential for hydrogenation. The depth of demineralization in the dentine is linked to this potential of the acidic monomer [12]. Depending on the degree of acidity, we classify them as: strong $\mathrm{pH}=1$, intermediate $\mathrm{pH} \sim 1.5$, slight $\mathrm{pH} \sim 2$, and ultra-low $\mathrm{pH}=2.5$. Those with a low $\mathrm{pH}$ or $\mathrm{pH}$ close to 1.5 contain functional monomers that mainly demineralize hard dental tissues; those with a $\mathrm{pH}$ greater than 1.5 partially demineralize the substrate, interacting chemically with the rest of the hydroxyapatite. On the other hand, ultra-low acidic monomers expose dentin collagen in a very superficially way [13-15].

This adhesive action in permanent dentition is not the same as in deciduous dentition for reasons such as dentin and enamel composition and structure, interfering with clinical bonding [16]. Dental substrates in deciduous dentition have a lower mineral content and less thickness than those in permanent dentition, along with a more accentuated prismatic layer in the enamel and a greater tubular density in the dentine, therefore reducing the intratubular area available for adhesion $[10,16,17]$. There is controversy in the results of different studies as to whether permanent substrates present more or less adhesion strength than deciduous ones. In this line, Pires et al. conducted a systematic review where they concluded that deciduous dentin had different fracture resistance and independent studies were needed [17]. A study published by Ghajari et al. reported significantly greater resistance to fracture in dentin in permanent teeth, confirming the need not to analyze both dentitions in the same group [18].

Based on the hypothesis that the different composition and $\mathrm{pH}$ of the universal adhesives used may interfere with the mechanical properties of the different universal adhesive systems, with the rise of adhesive systems in dental medicine, these materials need to be analyzed to identify the best strategy for clinical use in order to choose the most suitable adhesive system in daily clinical practice. Therefore, the aim of the study is to evaluate the bond strength of three universal adhesives on the deciduous tooth structure and their relationship with composition and $\mathrm{pH}$ by means of a mechanical micro push-out study and by studying the corresponding fracture type.

\section{Materials and Methods}

\subsection{Study Design}

A total of 150 deciduous extracted molars were divided into 3 restorative groups $(n=50)$ to evaluate the bond strength of three universal adhesives. The sample size was determined using Epidat 2.0 software (The EpiData Association, Odese M, Denmark). A minimum of 50 specimens was required in each group for a power of $80 \%$, assuming a common standard deviation of 2.10 and a significance level of 0.05 based on a previous pilot study.

The study was performed in accordance with national regulatory requirements, the ethical principles of the Declaration of Helsinki for medical research involving human subjects. It was evaluated and approved by the Ethics Committee for Research at the Clínico San Carlos Hospital in Madrid, Spain (registration code of the study: CEIC 20/398-E). Written informed consent was obtained from all the participants' parents.

\subsection{Study Groups}

The specimens were randomly divided into 3 groups $(n=50)$; two adhesives were used as self-etchers (experimental groups)—Adhese ${ }^{\circledR}$ Universal (Ivoclar Vivadent AG, Schaan, 
Liechtenstein) (ADH) and Futurabond ${ }^{\circledR} \mathrm{U}$ (Voco GmbH, Cuxhaven, Germany) (FUT) and the third group (control group) had a total-etch adhesive prior to the application of Scotchbond ${ }^{\mathrm{TM}}$ Universal (3M ESPE, St. Paul., MN, USA) (SCO) (Table 1).

Table 1. Composition and $\mathrm{pH}$ of adhesives used.

\begin{tabular}{|c|c|c|c|c|}
\hline Adhesive & pH Maker & Commercial Brand & Composition & pH Study \\
\hline $\mathrm{ADH}$ & $2.5-3$ & $\begin{array}{c}\text { Adhese }^{\circledR} \text { Universal } \\
\text { (Ivoclar Vivadent } \\
\text { AG, Schaan, } \\
\text { Liechtenstein) }\end{array}$ & $\begin{array}{l}\text { Methacrylates (10-MDP } \\
\text { and MCAP), HEMA, } \\
\text { Bis-GMA, D3MA, } \\
\text { ethanol, water, highly } \\
\text { dispersed silicon } \\
\text { dioxide, initiators, and } \\
\text { stabilizers }\end{array}$ & 3.7 \\
\hline FUT & 2.3 & $\begin{array}{l}\text { Futurabond }{ }^{\circledR} \mathrm{U} \\
\text { (Voco GmbH, } \\
\text { Cuxhaven, } \\
\text { Germany) }\end{array}$ & $\begin{array}{l}\text { 10-MDP, 2-HEMA, } \\
\text { Bis-GMA, acid } \\
\text { monomer adhesive, } \\
\text { dimethacrylate } \\
\text { urethane, catalyst, silica } \\
\text { nanoparticles, ethanol }\end{array}$ & 2.4 \\
\hline $\mathrm{SCO}$ & 2.7 & $\begin{array}{l}\text { Scotchbond }^{\mathrm{TM}} \\
\text { Universal (3M ESPE, } \\
\text { St. Paul., MN, USA) }\end{array}$ & $\begin{array}{c}\text { 10-MDP, Vitrebond } \\
\text { copolymer, HEMA, } \\
\text { Bis-GMA, } \\
\text { dimethacrylate resin } \\
\text { filler, silane, initiators, } \\
\text { ethanol, water }\end{array}$ & 3.2 \\
\hline
\end{tabular}

In order to confirm the data provided by the manufacturer on the $\mathrm{pH}$ of the adhesives used in the study, we carried out our own measurements using a $\mathrm{pH}$ meter in the laboratories of the Department of Inorganic Chemistry, Faculty of Chemistry, Complutense University of Madrid (Crison Instruments, SA, Barcelona, Spain) (Table 1).

\subsection{Specimen Preparation}

The occlusal dentine surface of each specimen was exposed using a polishing machine (Struers Dap-7 polishing machine) with coarse sandpaper and with the help of a tungsten bur at fast speed and abundant irrigation (Figure 1a).

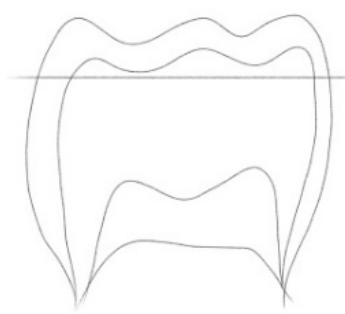

(a)

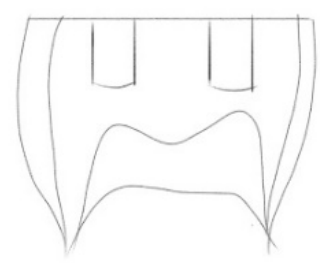

(b)

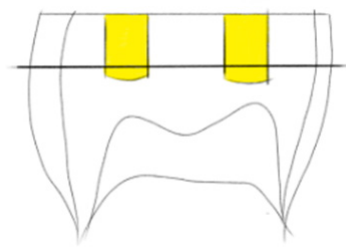

(c)

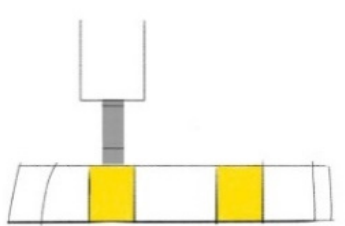

(d)

Figure 1. Illustration of specimen preparation and mechanical test of the study. (a) Enamel elimination; (b) cavity preparation; (c) cavity filing and sample cutting; (d) micro push-out test.

A type I black cavity was prepared with a round tungsten turbine bur (H1.314.016) with a $1.6 \mathrm{~mm}$ diameter and a $2 \mathrm{~mm}$ depth (Figure $1 \mathrm{~b}$ ). The corresponding adhesive system was applied, and the cavity was filled with composite (Voco GmbH A2 Grandioso, Cuxhaven, Germany) according to the experimental group and the instructions of its manufacturer. The teeth were sectioned off transversely to their longitudinal axis using a cutting machine (Exact ${ }^{\circledR}$ Cutting Unit 400C, Exact Tools Oy, Helsinki, Finland) and 
abundant irrigation (Figure 1c). The samples that could not be fixed due to their small size were placed in an acrylic block (self-curing acrylic material, Dentsply, Germany).

\subsection{Micro Push-Out Technique}

Each specimen was mechanically tested with Hounsfield Universal Test Equipment ${ }^{\circledR}$ (Croydon, England) (Figure 2a), exerting the load by means of its cylindrical steel punch, centered on the restoration, with no contact with the adjacent dentine until failure was achieved (Figures $1 \mathrm{~d}$ and $2 \mathrm{~b}$ ). For each specimen, the bond strength was calculated in MPa in the following equation: Failure load $(\mathrm{N}) /$ Bonding interface area $\left(\mathrm{mm}^{2}\right)$. The bonding interface area was calculated using the formula for the side surface of a cylinder [19]: $\mathrm{A}=2 \pi \mathrm{rh}$. During the mechanical tests, a standard loading speed of $0.5 \mathrm{~mm} / \mathrm{min}$ was applied. The values obtained were recorded by Metrotest's advanced testing software.

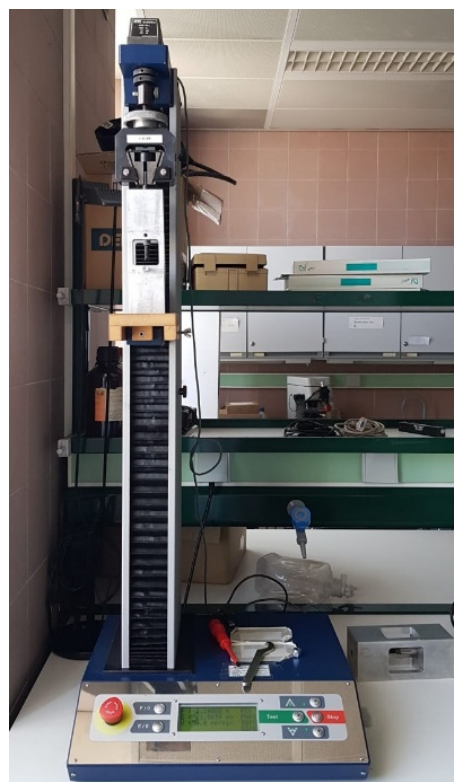

(a)

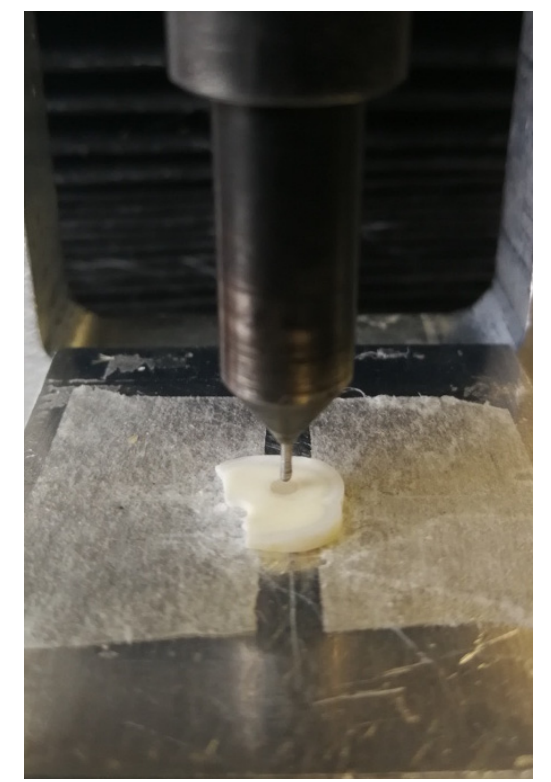

(b)

Figure 2. (a) Hounsfield Universal Test Equipment ${ }^{\circledR}$ (Croydon, England); (b) cylindrical steel punch centered on the specimen in the Universal Test Machine.

The failure type was examined using a Leica ${ }^{\circledR}$ MZ 12 stereomicroscope (Leica, Bensheim, Germany) (9.2× magnification) and classified into three categories: adhesive fracture between composite and dentin, cohesive, and mixed.

\subsection{Statistical Analysis}

A statistical and descriptive analysis of the adhesion strength variable was performed. The exploration was carried out using a box plot, a Q-Q plot of adjustment to normality and the histogram, and the Kolmogorov-Smirnov goodness test.

Descriptive analysis was performed with the usual tools: the range of observed values, mean, and standard deviation. For a significance contrast of the means, the 1-factor ANOVA test was chosen. Frequencies and percentages were calculated for the analysis of the type of fracture. The chi-squared test was used to examine the relationship between the variable type of adhesive and the form of failure. A 1-factor ANOVA test was used to verify the relationship between bond strength values and the type of fracture (IBM Corp, released 2017, IBM SPSS Statistics v 25.0 for Windows; Armonk, NY, USA). 


\section{Results}

The samples were evaluated per adhesive group $(n=50)$ and in total $(n=150)$ according to their fracture resistance variable (MPa). The average value of the $\mathrm{ADH}$ group was $13.66 \pm 2.81$; for FUT, it was $14.48 \pm 2.88$; for $\mathrm{SCO}$, it was $14.98 \pm 3.96$ (Table 2).

Table 2. Bond strength descriptive analysis. Variable adhesion strength depending on the type of adhesive $(n=50)$ and in the total sample $(n=150)$.

\begin{tabular}{cccccccccc}
\hline & \multicolumn{2}{c}{ Exploration Form } & \multicolumn{2}{c}{ Centrality } & \multicolumn{3}{c}{ Variability } \\
\hline $\begin{array}{c}\text { Bond Strength } \\
\text { Subgroup }\end{array}$ & Asymmetry & Curtosis & $\begin{array}{l}\text { KS Test: } \\
p \text {-value }\end{array}$ & Mean & Median & $\begin{array}{c}\text { Range } \\
(\text { Min/Max) }\end{array}$ & $\begin{array}{c}\text { SD } \\
\text { Interquartile } \\
\text { range }\end{array}$ \\
\hline ADH & 0.76 & 0.03 & $0.209^{\mathrm{NS}}$ & 13.66 & 13.07 & $9.84 / 21.3$ & 2.81 & 4.07 \\
\cline { 2 - 10 } FUT & 0.92 & 0.89 & $0.114^{\mathrm{NS}}$ & 14.48 & 13.57 & $10.34 / 23.66$ & 2.88 & 4.36 \\
SCO & 0.12 & 0.65 & $0.504^{\mathrm{NS}}$ & 14.98 & 14.07 & $8.74 / 28.75$ & 3.96 & 5.31 \\
\hline AF & Asymmetry & Curtosis & $\begin{array}{c}\text { KS Test: } \\
p \text {-value }\end{array}$ & Mean & Median & $\begin{array}{c}\text { Range } \\
(\text { Min/Max) }\end{array}$ & $\begin{array}{c}\text { SD } \\
\text { Interquartile } \\
\text { range }\end{array}$ \\
\hline Group Total & 1.16 & 1.88 & $0.015^{*}$ & 14.37 & 13.4 & $8.74 / 28.75$ & 3.28 & 4.36 \\
\hline
\end{tabular}

NS: Not significant deviation ( $p>0.05)$; the variable is normally distributed; * slight significant deviation $(p<0.05)$, the variable tends towards the normal model; AF: adhesion failure.

The normality of the distribution of the variables was accepted, and the one-way ANOVA test showed the absence of statistical significance between the groups, except for the means of $\mathrm{ADH}$ and $\mathrm{SCO}$, which presented a tendency towards statistical significance $p=0.057$ (Table 3). As a result, the ADH group had lower adhesion strength than the SCO group, and the FUT group values were very close to the control SCO with pre-conditioning.

Table 3. Comparative inferential analysis: 1-factor ANOVA. Adhesion strength for resistance to fracture, depending on the type of adhesive $(n=50)$.

\begin{tabular}{cccccc}
\hline \multirow{2}{*}{ Type of Adhesive } & \multicolumn{2}{c}{ Descriptive Statistics } & \multicolumn{2}{c}{ Paired Test Signification } \\
\cline { 2 - 6 } & Mean (SD) & $\mathbf{9 5 \%}$ CI & ADH & FUH & SCO \\
\hline ADH & $13.66(2.81)$ & $12.87-14.46$ & - & $0.418^{\text {NS }}$ & $0.057^{\text {NS }}$ \\
\hline FUT & $14.48(2.89)$ & $13.67-15.31$ & - & - & $0.728^{\text {NS }}$ \\
\hline SCO & $14.98(3.96)$ & $13.86-16.11$ & - & - & - \\
\hline
\end{tabular}

SD: standard deviation; CI: confidence interval; ${ }^{\mathrm{NS}}$ : not significant deviation $(p>0.05)$.

The most frequent type of failure was mixed $(60.7 \%)$, followed by adhesive $(27.3 \%)$ and cohesive (12\%). Using the chi-square test, the variable type of failure and the type of adhesive used were crossed without finding statistical evidence that relates them. Using the ANOVA test, the relationship between the AF values and the type of fracture was checked; the results (Table 4) showed that the values were higher when it was an adhesive fracture (14.66 MPa) or mixed (14.34 MPa) and lower when it was cohesive (13.92 MPa), without any statistical significance.

Table 4. Comparative inferential analysis: 1-factor ANOVA. Bond strength for resistance to fracture, depending on the type of fracture.

\begin{tabular}{ccccccc}
\hline \multirow{2}{*}{ Type of Fracture } & \multicolumn{3}{c}{ Descriptive Analysis } & \multicolumn{2}{c}{ Paired Test Signification } \\
\cline { 2 - 7 } & $\mathbf{N}$ & Mean SD & $\mathbf{9 5 \%}$ CI & Adhesive & Cohesive & Mixed \\
\hline Adhesive & 41 & $14.66(3.63)$ & $13.52-15.81$ & - & $0.46^{\text {NS }}$ & $0.608^{\text {NS }}$ \\
\hline Cohesive & 18 & $13.92(3.38)$ & $12.24-15.60$ & - & - & $0.606^{\text {NS }}$ \\
\hline Mixed & 91 & $14.34(3.13)$ & $13.69-15.00$ & - & - & - \\
\hline SD: standard deviation; CI: confidence interval; ${ }^{\text {NS }}$ : not significant deviation $(p>0.05)$. &
\end{tabular}




\section{Discussion}

Universal adhesive systems have very similar chemical compositions; the difference in the proportion and quantity of the elements influence the penetration of the adhesive into demineralized dentine [20]. The adhesives used in this study share some components: a hydrophilic monomer (HEMA, hydroxyethyl methacrylate) that facilitates the diffusion of resin in wet collagen and increases susceptibility to hydrolysis [21], and a hydrophobic monomer (Bis-GMA, bisphenol A-glycidyl methacrylate). They include solvents such as water and ethanol (which are essential for the composition of adhesives that need to be bonded to dentine), silane, dimethacrylate resins, initiators, and stabilizers. The main compound is the 10-MDP monomer, which interacts with the residual hydroxyapatite surrounding the collagen fibers, thus improving bond strength. Furthermore, the bond of 10-MDP to calcium creates a salt (MDP-Ca) that protects against hydrolysis as it is a hydrolytically stable salt [12]. Regarding the differences in chemical composition, MCAP, urethane dimethacrylate, and the Vitrebond copolymer stand out. Using a $\mathrm{pH}$ meter (Crison Instruments, SA, Barcelona, Spain), we measured the $\mathrm{pH}$ of the adhesives and found that there were differences with the data provided by the manufacturers (Table 1). Due to the rapid growth of adhesive systems and their diverse characteristics, each of them should be analyzed to identify the best mechanical properties and strategy of use.

The in vitro mechanical micro push-out test results showed similar adhesion strength between the self-etching FUT and SCO with prior acid etching and a greater, although not significant, difference between $\mathrm{SCO}$ and $\mathrm{ADH}$. ADH, with an ultra-high $\mathrm{pH}$ of 2.5-3, would have a lower capacity to dissolve the smear layer and demineralize the underlying dentine surfaces when applied as a self-etch [16,17]. Therefore, this statement could explain the lower fracture resistance compared with the other adhesive systems used in the study. The control SCO has a lower acidic $\mathrm{pH}$, similar to $\mathrm{ADH}$, but its pre-conditioning with orthophosphoric acid would have improved the penetration of the resin into the dentine. Such a pre-etching strategy is more sensitive to the operator, but the presence of MDP, the polyalkenoic acid copolymer (Vitrebond), and silane in its composition allows the hydration of collagen, creating the hybrid layer even in dry demineralized dentine [3]. Vitrebond is the exclusive component in this system, causing a chemical and spontaneous bond to the hydroxyapatite, showing greater adhesion strength than if it were not present [6].

In this study, the two adhesives used as self-etchers present different results: ADH $13.66<$ FUT $14.48 \mathrm{MPa}$, in accordance with their results with the ultra-high $\mathrm{pH}$ of the ADH group (2.7-3), and more acidic pH of the FUT group (2.3). The FUT adhesive, with a mild $\mathrm{pH}$ degree, obtained similar mechanical results when compared to the control. That result could be due to traces of hydroxyapatite remaining for chemical interaction with a functional monomer [3]. A higher $\mathrm{pH}$ does not guarantee a higher bond strength, and the use of different solvents will not influence the results [9]. There could be a lack of knowledge by manufacturers in the application of self-etching agents, which improve properties by increasing the number of coats when applied [22]. The FUT adhesive, in turn, presented in a single dose, would avoid the deterioration of the compound's properties and the evaporation of solvents, besides being a faster and easier application. Regarding the hydrogen ion's potential and bond strength, we conclude that a more basic $\mathrm{pH}$ adhesive could mean a lower resistance to fracture. It could improve mechanical properties by acidifying the adhesive by lowering the $\mathrm{pH}$ or by applying previous conditioning, taking against the latter option the need for greater dexterity by the clinician and the possible appearance of post-operative tooth sensitivity. If acidifying the adhesive is chosen, the one-step self-etching strategy should be used, which is especially useful for pediatric patients due to its speed.

Regarding failure type, mixed fractures were more frequently reported, in agreement with Cunha and Dos Santos [23,24]. In the present study, it was associated with higher adhesion strength to adhesive and mixed fractures, although without significance, similar to the findings of Egilmez et al. [25]. However, Alonso and Brandt et al. found minimal cohesive failure, in agreement with the present study, yet associated with the group with 
higher adhesion strength, perhaps due to the diverse methodology employed, namely, preparation in bovine dentition [26,27].

There is a lack of homogeneity among the used criteria regarding the pre-conditioning of dentin in primary dentition. Some authors have concluded that this is a result of higher bond strength if the substrate is pre-conditioned $[2,3,28,29]$, similar to the results of the SCO group in this study $(14.98 \pm 3.96 \mathrm{MPa})$. However, Thanaratikul et al. reported no difference, according to the strategy used on dentin in pediatric patients [30]. On the other hand, Kensche et al. obtained different results depending on the adhesive and its composition, regardless of the strategy used [31]. Overall, many authors have concluded that the differences are due to the different composition of the universal adhesives rather than the methodology used [5]. The lack of significance, especially between the two-step control SCO and the universal adhesive as a self-etching FUT, could indicate an approach to the objectives of finding simpler and faster techniques for the treatment of pediatric patients in the clinic. Further randomized clinical trials are recommended in order to assess the longevity of different universal adhesives on the deciduous tooth structure to demonstrate their effectiveness in a real clinical scenario.

\section{Conclusions}

Within the limitations of the present study, the following conclusions can be drawn:

- FUT, with a lower $\mathrm{pH}$ of 2.3, presents higher penetration capacity at the dentin tubule, providing greater fracture resistance with a self-etching strategy.

- Despite the fact that SCO has an ultra-low $\mathrm{pH}$ of 2.7, its adhesion strength is improved when combined with a previous acid etching.

- There was no statistical significance when relating failure to the type of adhesive.

Author Contributions: Conceptualization, R.M.D.R.C., V.V.-G. and M.R.M.-M.; methodology, R.M.D.R.C., V.V.-G. and M.R.M.-M.; software, R.M.D.R.C. and P.R.V.; validation, R.M.D.R.C., V.V.-G. and M.R.M.-M.; formal analysis, R.M.D.R.C., V.V.-G. and M.R.M.-M.; investigation, R.M.D.R.C.; resources, P.M.-M., M.F., V.V.-G. and M.R.M.-M.; data curation, R.M.D.R.C., P.M.-M., P.R.V. and E.C.; writing-original draft preparation, R.M.D.R.C., P.M.-M., V.V. and E.C.; writing-review and editing, R.M.D.R.C., P.M.-M., E.C. and V.V.; visualization, P.M.-M. and M.F.; supervision, V.V.-G., M.F. and M.R.M.-M.; project administration, R.M.D.R.C., V.V.-G. and M.R.M.-M.; funding acquisition, V.V.-G. and M.R.M.-M. All authors have read and agreed to the published version of the manuscript.

Funding: This research received no external funding.

Institutional Review Board Statement: The study was conducted according to the guidelines of the Declaration of Helsinki in accordance with national regulatory requirements for medical research involving human subjects and approved by the Institutional Ethics Committee for Research at the Clínico San Carlos Hospital in Madrid, Spain (registration code of the study: CEIC 20/398-E).

Informed Consent Statement: Written informed consent was obtained from the parents of all participants.

Data Availability Statement: The data that support the findings of this study are available from the corresponding author, P.M.-M., upon reasonable request.

Acknowledgments: The authors would like to thank to the Postgraduate Programme in Pediatric Dentistry (Complutense University of Madrid, Spain) for its assistance in this study.

Conflicts of Interest: The authors declare no conflict of interest.

\section{References}

1. Mandri, M.N.; Aguirre Grabre de Prieto, A.; Zamudio, M.A. Adhesive systems in restorative dentistry. Odontoestomatologia 2015, $17,50-56$.

2. Lenzi, T.L.; Soares, F.Z.M.; Raggio, D.P.; Pereira, G.K.R.; Rocha, R.D.O. Dry-bonding etch-and-rinse strategy improves bond longevity of a universal adhesive to sound and artificially-induced caries-affected primary dentin. J. Adhes. Dent. 2016, 18, 475-482. [CrossRef]

3. Lenzi, T.L.; Soares, F.Z.M.; De Oliveira Rocha, R. Does bonding approach influence the bond strength of universal adhesive to dentin of primary teeth? J. Clin. Pediatr. Dent. 2017, 41, 214-218. [CrossRef] [PubMed] 
4. Scotti, N.; Cavalli, G.; Gagliani, M.; Breschi, L. New adhesive and bonding techniques. Why and when? Int. J. Esthet. Dent. 2017, 12, 524-535. [PubMed]

5. Muñoz, M.A.; Sezinando, A.; Luque-Martinez, I.; Szesz, A.L.; Reis, A.; Loguercio, A.D.; Bombarda, N.H.; Perdigao, J. Influence of a hydrophobic resin coating on the bonding efficacy of three universal adhesives. J. Dent. 2014, 42, 595-602. [CrossRef] [PubMed]

6. Tsujimoto, A.; Barkmeier, W.W.; Takamizawa, T.; Watanabe, H.; Johnson, W.W.; Latta, M. Comparison between universal adhesives and two-step self-etch adhesives in terms of dentin bond fatigue durability in self-etch mode. Eur. J. Oral Sci. 2017, 125, 215-222. [CrossRef]

7. Michaud, P.L.; Brown, M. Effect of universal adhesive etching modes on bond strength to dual-polymerizing composite resins. J. Prosthet. Dent. 2018, 119, 657-662. [CrossRef]

8. Van Landuyt, K.L.; Snauwaert, J.; De Munck, J.; Peumans, M.; Yoshida, Y.; Poitevin, A.; Coutinho, E.; Suzuki, K.; Lambrechts, P.; Van Meerbeek, B. Systematic review of the chemical composition of contemporary dental adhesives. Biomaterials 2007, 28, 3757-3785. [CrossRef] [PubMed]

9. Bedram-Russo, A.; Leme-Kraus, A.A.; Vidal, C.M.P.; Teixeira, E.C. An overview of dental adhesive systems and the dynamic tooth-adhesive interface. Dent. Clin. North Am. 2017, 61, 713-731. [CrossRef]

10. Lenzi, T.L.; Raggio, D.P.; Soares, F.Z.M.; Rocha, R.D.O. Bonding performance of a multimode adhesive to artificially-induced caries-affected primary dentin. J. Adhes. Dent. 2015, 17, 125-131. [CrossRef]

11. Chen, C.; Niu, L.N.; Xie, H.; Zhang, Z.Y.; Zhou, L.Q.; Jiao, K.; Chen, J.H.; Pashley, D.H.; Tay, F.R. Bonding of universal adhesives to dentine-Old wine in new bottles? J. Dent. 2015, 43, 525-536. [CrossRef] [PubMed]

12. Manfroi, F.B.; Marcondes, M.L.; Somacal, D.C.; Borges, G.A.; Burnett, L.H., Jr.; Spohr, A.M. Bond strength of a novel one bottle multi-mode adhesive to human dentin after six months of storage. Open Dent. J. 2016, 10, 268-277. [CrossRef] [PubMed]

13. Lührs, A.K.; Gurh, S.; Schilke, R.; Borchers, L.; Geurtsen, W.; Günay, H. Shear bond strength of self-etch adhesives to enamel with additional phosphoric acid etching. Oper. Dent. 2008, 33, 155-162. [CrossRef] [PubMed]

14. Van Meerbeek, B.; Yoshihara, K.; Yoshida, Y.; Mine, A.; De Munck, J.; Van Landuyt, K.L. State of the art of self-etch adhesives. Dent. Mater. 2011, 27, 17-28. [CrossRef] [PubMed]

15. Matos, A.B.; Trevelin, L.T.; Silva, B.T.F.; Francisconi Dos Rios, L.F.; Siriani, L.K.; Cardoso, M.V. Bonding efficiency and durability: Current possibilities. Braz. Oral Res. 2017, 31,3-22. [CrossRef]

16. Lenzi, T.L.; Gimenez, T.; Tedesco, T.K.; Mendes, F.M.; Rocha, R.d.O.; Raggio, D.P. Adhesive systems for restoring primary teeth: A systematic review and meta-analysis of in vitro studies. Int. J. Paediatr. Dent. 2016, 26, 364-375. [CrossRef]

17. Marquezan, M.; Da Silveira, B.L.; Burnett, L.H., Jr.; Rodrigues, C.R.; Kramer, P.F. Microtensile bond strength of contemporary adhesives to primary enamel and dentin. J. Clin. Pediatr. Dent. 2008, 32, 127-132. [CrossRef]

18. Pires, C.W.; Soldera, E.B.; Bonzanini, L.I.L.; Lenzi, T.L.; Soares, F.Z.M.; Montagner, A.F.; Rocha, R.D.O. Is adhesive bond strength similar in primary and permanent teeth? A systematic review and meta-analysis. J. Adhes. Dent. 2018, 20, 87-97. [CrossRef]

19. Ghajari, M.F.; Ghasemi, A.; Badiee, M.; Abdolazimi, Z.; Baghban, A.A. Microshear Bond Strength of Scotchbond Universal Adhesive to Primary and Permanent Dentin: A Six-Month in Vitro Study. Front. Dent. 2019, 16, 173-180. [CrossRef]

20. Aguilar-Mendoza, J.A.; Rosales-Leal, J.I.; Rodríguez-Valverde, M.A.; González-López, S.; Cabrerizo-Vílchez, M.A. Wettability and bonding of self-etching dental adhesives. Influence of the smear layer. Dent. Mater. 2008, 24, 994-1000. [CrossRef]

21. Takamizawa, T.; Barkmeier, W.W.; Tsujimoto, A.; Berry, T.P.; Watanabe, H.; Erickson, R.L.; Latta, M.A.; Miyazaki, M. Influence of different etching modes on bond strength and fatigue strength to dentin using universal adhesive systems. Dent. Mater. 2016, 32, 9-21. [CrossRef] [PubMed]

22. Ozmen, B.; Koyuturk, A.E.; Tokay, U.; Cortcu, M.; Sari, M.E. Evaluation of bond strength of self-etching adhesives having different pH on primary and permanent teeth dentin. J. Appl. Biomater. Funct. Mater. 2015, 13, 274-279. [CrossRef] [PubMed]

23. Fujiwara, S.; Takamizawa, T.; Barkmeier, W.W.; Tsujimoto, A.; Imai, A.; Watanabe, H.; Erickson, R.L.; Latta, M.A.; Nakatsuka, T.; Miyazaki, M. Effect of double-layer application on bond quality of adhesive systems. J. Mech Behav. Biomed. Mater. 2018, 77, 501-509. [CrossRef] [PubMed]

24. Cunha, L.G.; Alonso, R.C.B.; Correr, G.M.; Brandt, W.C.; Gorrer-Sobrinho, L.; Sinhoreti, M.A.C. Effect of different photoactivation methods on the bond strength of composite resin restorations by push-out test. Quintessence Int. 2008, 39, $243-249$.

25. Dos Santos, P.J.; Silva, M.S.; Alonso, R.C.B.; D'Alpino, P.H.P. Hydrolytic degradation of silorane-and methacrylate-based composite restorations: Evaluation of push-out strength and marginal adaptation. Acta Odontol. Scand. 2013, 71, 1273-1279. [CrossRef]

26. Egilmez, F.; Ergu, G.; Cekic-Nagas, I.; Vallittu, P.K.; Lassila, L.V.J. Bond strength of self-adhesive resin cements to dentin after antibacterial and chelating solution treatment. Acta Odontol. Scand. 2013, 71, 22-31. [CrossRef] [PubMed]

27. Alonso, R.C.B.; Cunha, L.G.; Correr, G.M.; Brandt, W.C.; Correr-Sobrinho, L.; Sinhoreti, M.A.C. Relationship between bond strength and marginal and internal adaptation of composite restorations photocured by different methods. Acta Odontol. Scand. 2006, 64, 306-313. [CrossRef]

28. Brandt, W.C.; De Moraes, R.R.; Correr-Sobrinho, L.; Sinhoreti, M.A.C.; Consani, S. Effect of different photo-activation methods on push out force, hardness and cross-link density of resin composite restorations. Dent. Mater. 2008, 24, 846-850. [CrossRef]

29. Kim, Y.; Kim, S.; Jeong, T.; Son, S.A.; Kim, J. Effects of additional acid etching on the dentin bond strengths of one-step self-etch adhesives applied to primary teeth. J. Esthet. Restor. Dent. 2017, 29, 110-117. [CrossRef] 
30. Thanaratikul, B.; Santiwong, B.; Harnirattisai, C. Self-etch or etch-and-rinse mode did not affect the microshear bond strength of a universal adhesive to primary dentin. Dent. Mater. J. 2016, 35, 174-179. [CrossRef]

31. Kensche, A.; Dähne, F.; Wagenschwanz, C.; Richter, G.; Viergutz, G.; Hannig, C. Shear bond strength of different types of adhesive systems to dentin and enamel of deciduous teeth in vitro. Clin. Oral Investig. 2016, 20, 831-840. [CrossRef] [PubMed] 